\title{
Mobile Learning: the Philosophical Challenges, Problems and Implications of Defining and Theorising
}

\begin{abstract}
This essay uses the popular and perennial topic of definition as a way to explore differing perspectives and expectations amongst the various communities whose interests and activities overlap in what has come to be called mobile learning, and to discuss the role and choice of theory in mobile learning. The purpose of the paper is to add to the academic foundations of mobile learning. These communities continue to make progress and continue also to make mistakes; the researchers continue to provide ideas and examples for practitioners, policy-makers, activists and developers, but often on assumptions, logic and inferences that are not transparent or robust. This is the problem being addressed. Here we seek to add greater critical rigour to the language and expectations being deployed. The essay is by nature not definitive, but seeks merely to expose some of the lack of clarity when mobile learning is discussed and promoted.
\end{abstract}

Keywords: mobile learning; choice of theory; academic foundations; assumptions; genus; differentia

\section{Defining Definitions}

The development of mobile learning has, throughout its first two decades, been bedevilled by discussions of definition that have hampered clarity, consensus and rigour. This paper seeks to look beneath these discussions and explore the relationships between what is being defined and how this is done.

In defining mobile learning, we must first explore briefly the nature of definitions. Returning to the basics of Aristotelian logic, definition is viewed as genus and differentia. In the case of mobile learning, the genus is learning, and the differentia is mobile. In effect, we are talking about the mobile sub-division of learning, implying that learning is unchanged but partitioned into mobile and presumably static versions. Is the most appropriate way to approach mobile learning, as a noun qualified by an adjective, as a modification of existing ideas about learning?

An alternative formulation looks at mobility as the genus (and mobility is, after all, now, a defining (sic) characteristic of our societies) and learning as the differentia. In 
this interpretation, mobile learning is the pedagogic or educational part of a mobile world. The division into genus and differentia does, however, suggest too sharp a division between the learning and the mobility. We have argued (Traxler 2011) that mobility and connectivity transform the nature of the epistemology that underpins pedagogy and learning. We have argued that they transform what we know, what we need to know, what we value knowing, how we come to know it, in short, mobile technologies accelerate and amplify what has been called the epistemological revolution started by digital computer technology (Des Bordes and Ferdi 2008). We must, however, see this revolution in the appropriate cultural contexts, taking into consideration the earlier epistemology characteristic of each culture and the nature of the demographics and technologies involved.

\section{Definitions Amidst Paradigm Shift}

One way to understand the relationship between these contrasting definitions might be to see them in terms of a paradigm shift (in strictly Kuhnian terms, Kuhn 2012), as we move from the centrality of the theories, conceptions and texts of the conventional tethered e-learning paradigm, with mobiles at the intellectual periphery, to a new paradigm that places mobility at the centre, driving a new research agenda, a new value system and a new - but still emergent - conceptual framework. Whilst the mobile learning community might not explicitly articulate the axioms of its paradigm, these were clearly derived from the aspirations, methods, funding, rhetoric and history (and indeed, the personnel and personalities) of the e-learning community and have given it a separate identity within the e-learning community. They underpin its definition of mobile learning, and they explain the provenance of our first definition, the mobile version of learning, implicitly the mobile version of digital learning.

The mobile learning paradigm espoused by this community is now however under threat at its periphery; that what are perceived as unimportant errors or problems, for example difficulties with sustainability, scale or evidence, in fact represent the crumbling of one paradigm and definition and the emergence of another, one to which these earlier discrepancies, errors or problems are the foundational truths. It is possible to portray learning with mobiles as about to undergo a paradigm shift from a position and definition where the research agenda was generated by a research community that grew up or grew out of desktop e-learning, using mobile technologies to enhance, 
extend and enrich the existing curricula, institutions and professions of education to another paradigm that defines mobile learning and situates it into an account of a mobile and connected society, the part of the account built on the ways in which people and communities generate, transform, discuss, share and transmit ideas, opinions, identities, images and information, as they move and connect.

If such a change is about to take place then any theorising about mobile learning takes place against a transformed background and on transformed foundations. The new foundational disciplines may include the sociology of mobilities (Hannam et al. 2006, Urry 2007) and the methodological toolkit may come from the same source (Büscher and Urry 2009). This in effect transforms and redefines what has been called "mobile learning" from the mobile component of learning, actually of e-learning with all its baggage, to the educational and pedagogic component of mobility and mobile societies. This explains the conceptual flip between our earlier sets of definitions; it is indeed a paradigm shift.

These could be seen as perspectives that respectively look backwards and forwards from an era when mobile technology was scarce, obscure, fragile, expensive, and other to an era when mobile technology has become universal, robust, easy, obvious, cheap, and is variously described as embodied or prosthetic (Rettie 2005).

This analysis does, however, only make sense within one particular cultural and historical framework, that of the academically and intellectually sophisticated university environment of the global North. Other environments would not share this history nor would they understand these particular accounts and tensions around competing ideas and definitions of "mobile learning".

The preceding discussion attempts definition by denotation, attempting to identify the essence, again an Aristotelian term, of mobile learning by separating what we know about mobile learning into essence and attributes. It is always in practice far too easy to confuse the essence of learning with mobiles, whatever that may be, and the attributes, that is, for example, of specific personal digital technologies. This was the problem of those earlier definitions that focused on technology, those that focused on a specific portfolio of devices. These definitions may also have taken the easy option, of focusing on aspects that were easy to identify and understand, rather than more abstract and nebulous concepts such as learning. 


\section{Defined by Practice}

There is also definition by connotation, where we point at the various instances of mobile learning in order to understand the defining essence. (Denotation might involve pointing at a canoe, a trawler, a liner and a tug in order to define "boat", whereas connotation might involve genus, 'artificial floating object' and differentia, "for transport". These terms are considerably more complex in semiotics, but this account seeks to make a practical point). This has proved useful in the past, where researchers have tried defining mobile learning in terms of its constituent projects, pilots and personnel, or perhaps in terms of constituent sub-categories of projects, pilots and personnel (viz. Traxler 2008, where projects are organized and analysed in order to expose - or rather, to impose - their latent order and essence). These may, however, be the activities of a self-defining and self-referential community, self-defining in the sense that researchers themselves identify their work as "mobile learning" and selfreferential in the sense of mutual citation, quotation and collaboration. They say in effect that mobile learning is defined by the community that attends mobile learning conferences and writes in mobile learning journals. It risks ignoring, for example, the work of the Open and Distance Learning (ODL community ${ }^{1}$ ) in exploiting mobiles, especially in areas of the world with less e-learning legacy and less static infrastructure, where the delivery and the support of learning are more urgent and more utilitarian concerning pragmatic issues.

In the context of definitions of learning, it would be interesting to hear about the impact of universal mobile technology on the nature and number of learning projects (Tough 1979) from an earlier generation. Although the initial paradigm of mobile learning worked within the institutions of formal education, the paradigm based within a mobile and connected society, where people generate, transform, consume and discuss images and information amongst themselves, severely undermines or perhaps demolishes the learning projects approach.

This approach might be defining mobile learning in the terms of the professional mobile learning community and this will be distinct from myriad individuals and communities responsible for the vast amount of user-generated content, in podcasts, web-sites and

${ }^{1}$ See, for example, Distance Education, 31: 2, 2010. 
apps being accessed for learning on the move. This is, however, an implied criticism of those that advocate definitions in terms of learning made mobile as opposed to those adopting the contrasting, educational-aspects-of-mobile-society definitions. The implied criticism may be overtly academic; while a scholarly minority define mobile learning, an amateur majority practise mobile learning. They just make use of this form of learning, whatever it may involve. It does, however, have implications outside academia since the way mobile learning is defined and conceptualised determines funding, responsibilities and priorities amongst officials, agencies and policy makers.

There is a relevant and useful distinction here between the espoused definitions of mobile learning and the enacted definitions. We have in effect been discussing the espoused definition, what people say about mobile learning, not their enacted definitions, what people actually do, and perhaps the latter is more conservative and narrow than the sweeping and progressive ideas that are widely espoused. Beyond the research community and often within it, mobile learning merely means retail apps, improved field trips and accessing Moodle whilst commuting; this is the definition that is enacted (challenged by Cochrane et al. 2016).

\section{After Modernity}

The discussion so far is essentially modernist; it subscribes to the belief that words and symbols generally, describe reality. A post-modern position is that words create reality, or rather they create or construct what we think is reality, especially social reality. There has been 15 years of scholarly discourse on mobile learning and this discourse has shaped expectations, practices and priorities. This is essentialising (Butler 2002), and the more abstract the idea, the more risks we take, risks that what we are talking about that actually exists as a coherent meaningful entity, risks that we are all talking about the same thing, risks that talking about something creates the impression it exists. Talking about mobile phones has been relatively safe - they are concrete, stable and bounded objects; talking about learning is more risky - for is learning a created reality in the language we use to describe it? In this sense, creating and defining the idea of mobile learning has inadvertently created a creed, a club, a brand, a filter and an orthodoxy, a worry about whether pilots or programmes qualify for inclusion, and this is clearly unhelpful 
At this point it might be relevant to say that this is a critique from the perspectives of European philosophy and language. Its validity is, however, questionable outside the Western European mind-set. We could argue that the English language, international corporates and American digital technology ensure the global hegemony of a kind of vulgar modernism (often building on European colonial and imperial legacies). Many scholars, however, implicate mobile technologies to a shift towards a wider but crude post-modernity in Europe and beyond (Kirby 2009) where the relationship between language and experience becomes far more problematic, and definitions exist in a more fluid, transient, partial and subjective context.

\section{The Historical and Cultural Specificity of Definitions}

Moving on from mobile learning's problematic definitions, in this section its historical and cultural roots are reviewed, in order to explore other forces that have shaped how mobile learning is understood, up to the current phase of its Americanisation/globalization, to expose the challenge of transplanting a concept that is often considered culturally-neutral. Early mobile learning literature does grow out of the concerns and aspirations of the European or Anglophone e-learning community. There have already been attempts to document the history, evolution and development of mobile learning (Kukulska-Hulme et al. 2011, Pachler et al. 2010). These are excellent accounts from early key players in European mobile learning research and are valuable for their scholarly and critical readings of events and concerns in the first decade of mobile learning.

There are also sources that give a more recent US or global perspective (Ally 2009, Cobcroft 2006, Crompton 2013, Herrington et al. 2009, Metcalf 2006, Quinn 2000, Schuler 2009). Recently, UNESCO has attempted a region-by-region review of global activity in mobile learning (Dykes and Knight 2012, Fritschi and Wolf 2012a, Fritschi and Wolf 2012b, Hylén 2012, Isaacs 2012a, Isaacs 2012b, Jara, Clairo, and Martinic 2012, Lugo and Schurmann 2012, So 2012). This latter review is by no means scientific, rigorous, comprehensive or systematic, but clearly reveals how geographically patchy and culturally specific mobile learning has been.

There seems to be little or no literature in most of the world's major languages, except English, and none in any of the world's other languages and few accounts from outside the early heartlands and hot-spots of Western Europe, mostly UK, Asia Pacific, 
meaning Japan, Singapore, Taiwan and Hong Kong, and South Africa, and latterly North America. Mobile learning in each of these regions takes on its own inflection - it is possible to characterize mobile learning in Africa as service delivery, in Europe as informal context learning, in North America as corporate drill and training and in Asia Pacific as seamless learning. These cultural contexts of mobile learning hint at the challenge of transferring into new and different cultural contexts.

\section{Moving Out of the Cradle}

Moving to the point at which mobile learning broke out of a small research community, it could be argued that the arrival of the iPhone in 2007 catalysed and epitomised the US interest in the mobile (or vice versa, perhaps). This led to an awareness and an interest amongst US agencies, such as DoD, USAID and the Peace Corps, amongst US foundations, such as Ganz Cooney, Macarthur and Hewlett Packard, and amongst international organisations staffed mainly by US nationals, such as the World Bank, World Economic Forum, UNESCO, UNHCR, the International Telecommunications Union, the International Labour Organisation to deliver their various humanitarian and educational missions in the global South.

Some of these agencies do, however, promote mobile technologies for learning within a technicist problem-solving paradigm (Wilson 2006), very explicitly aiming a silver bullet from the developed North to the different and developing South. If international development were merely culturally neutral catching-up or modernization then this would be unproblematic (Toyama 2015) - or would it?

This change was accompanied by a greater awareness amongst corporates, for example, Nokia, Pearson and the MNOs represented by the GSMA, of the commercial potential education offers to the global South in their portfolios, the GSMA talking of the next billion subscribers and of "A Platform for Educational Opportunities at the Base of the Pyramid" in 2010. This period also saw the emergence of the apps economy (Genachowski 2010) and the growth of user-generated web2.0 learning (Cook 2010), not only apps across every major platform but e-books, blogs, web-sites and communities, often originating outside the domains of commercial developers, professional educators and academic researchers. This marked a shift in balancing different pedagogies of mobile learning activities as well an enormous increase in scale. 
In the broadest terms, these changes also demonstrated increasing diversity in expressions of sustainability and in underlying business models for mobile learning.

There was increased pressure from among the newly interested policy, commercial and donor communities in scale and sustainability. This pressure was not wholly benign, representing a threat and a challenge to the earlier pedagogic richness and to the primacy of purely educational concerns. Localisation was promoted as a response in favour of non-US English cultures and whilst ostensibly a culturally-neutral and linguistically neutral process ensuring equivalent access and relevance in practice means translating (but not transferring) American English content and practices into other languages delivered through American designed technologies. It is difficult to identify the extent of the influence on language, discourse and literacy of largely US technologies on the languages of the world, both major and minor (Traxler 2016).

The shift in the centre of gravity towards the US may also have produced a greater interest in games, drill and training at the expense of the earlier theoretically informed informal and contextual learning. The imperative to scale may have shifted the emphasis towards models of learning based upon content and its delivery and away from models based on discussion, community and connection. The imperative to scale may have favoured formal learning over informal learning and may have favoured education for the mainstream over education for the marginal. National and international interest in 'objective' testing regimes across primary and secondary sectors may also have influenced the market for mobile learning interventions.

The emergent players may have reinforced the existing monopoly of US English as the preferred education medium. At the same time, researchers were displaced by consultants and advisors as mobile technologies became accessible, easy and universal and learning with mobiles became apparently obvious and commonsensical. The sophisticated and rigorous theorising of the early mobile learning research community, coming out of one set of cultural contexts, was replaced by simpler theorising, from a different community and cultural context.

Research funding, the nature of the funding ecosystem, the dominant research questions and the early technical challenges may have diverted attention from sustainability and the occasional donations from corporates (Corporate Social Responsibility, CSR), often short-term, and in the form of air-time or handsets) may have pressurised researchers 
to work within constrained methods, shortened timescales and to work for more objective quantifiable outcomes. (It is also the case that many education systems are experiencing increased pressure from test regimes.)

This changed environment for mobile learning introduced a new balance and emphasis in the activities understood as mobile learning and a problematic synergy between hegemonic (US) English content, global (publishing, media, telecoms) corporations and an implicitly US technology (hardware, software, interfaces, interactions, gestures and connectivity). The significance here is the transformation in the cultural context and cultural specificity of mobile learning.

Much of the evidence on mobile learning is coming from a small number of leading exponents in a small number of countries, predominantly UK and South Africa, followed by Western Europe, North America and Asia Pacific. This is a small sample from which to generalise even before we recognise that each of these regions have their own inflection of mobile learning. The literature in Chinese, Russian, Arabic, Swahili and most other languages is minimal by comparison. Differences in tariffs and regulatory frameworks, amongst a myriad of other details, are further confounding factors confronting easy generalisation.

We argue that as mobile learning moved from academic research to ministerial policy, considerable wishful but flawed thinking took place, driven by the desire to do good but within certain constrained parameters, pressure and understanding. Whilst these may represent the workings of the international community they are still located in a specific cultural and historical context. These remarks illustrate how the various communities and stakeholders now involved in mobile learning may understand it differently and how perhaps they need to understand it differently in order to portray something that will serve their respective interests.

\section{Culture and Causation}

The significance of defining mobile learning is clearly related to explaining it, specifically for researchers, policy-makers and practitioners, explaining what makes it happen, what are the causes and effects, what is narrative and what is anecdote? Fundamentally, these different communities want to know what makes good mobile learning happen? 
The fashion for different kinds of causal explanation ranging from the individualistic hero-innovator accounts (Storey 2000) to socio-economic accounts depends on historical, cultural and political preferences. In the global North West, it could be argued that the dominant implicit scientism (Rose and Rose 1976, Sorell 2013) underpins much of the preference for evidence - as opposed to expertise or experience, for example since the 1940s. The institutions of the global North and historically of the global North West have shaped the dominant global paradigm of higher education, again in a literally Kuhnian sense, determining the research agenda, the authoritative personnel, the professional hierarchies, the preferred formats, the funding mechanisms and the acceptable forms of reasoning that characterise how knowledge is manufactured, distributed and consumed. This has shaped the direction of mobile learning research and the emergence of a possibly misguided quest for evidence that becomes progressively less relevant or meaningful as mobiles become ubiquitous and pervasive, no longer worth noticing and no longer worth justifying. In fact, the prevalent scientism, expressed as evidence-based policy formulation, may have portrayed the role of the research community as the production of evidence rather than the production of experts or expertise or the accretion of experience. The problematic relationships between research, policy, impact and funding in the global North West have led to cynicism about policy-based evidence formulation. We should add that logically there is no evidence for evidence, and expecting that there would be, is circular and self-referential (Traxler 2008).

These developments also exposed mobile learning practice, practitioners and theories to different kinds of audience and different kinds of scrutiny, and to some extent, they exposed the flaws and misconceptions in the relationships between mobile learning researchers and the policy, management and institutional communities. This has been explored in the UNESCO publications (Traxler 2016) but is significant for highlighting the issues of using and transferring research findings into educational policy, funding programmes and organisational priorities at a local or national level.

\section{Theories and Theories of Theories}

Theory is increasingly important as learning with mobiles becomes more popular and widespread. Theory may provide insights into causality, its scope and relevance. Practitioners, managers and policy-makers, and the population as a whole, have become 
more familiar and confident with increasingly powerful mobile technologies. As learning with mobiles becomes in some senses self-explanatory and self-evident, theorists have dropped out of the picture as ministries, agencies, and corporations invest in learning with mobiles - theory is no longer necessary. In fact, theory still operates in this new configuration, but often it is simplistic, uncritical and tacit in the form of clichés or exhortations such as keep it simple stupid or content is king. This is difficult when mobile learning research itself is sometimes short on theory: an early review of the mobile learning research literature (Traxler and Kukulska-Hulme 2006) found many accounts of research projects that were not always based rigorously and robustly on a theoretical underpinning (and of course, these theories would have grown up within the prevalent mobile learning paradigm).

Theory, and its defining paradigm, affect what we observe, what we perceive, how we explain what we observe, what we deem valuable, what we deem subject and/or object, and how we connect observations, values, and existing "knowledge" (Neuman 2003). To an extent, theoretical work is akin to 'sense-making' (Weick and Sutcliffe 2005), but through a lens that looks both forward and backward in an effort to both evaluate and rationalise practices and beliefs, difficult in times of such flux.

The theoretical tools we use can shape what we see and what we make. Barad (2007) suggests that the choice of apparatus being used in research determines which properties become determinate and are not solely under the direct control of the researcher, only once we choose the narrative do some of our experiences get relegated to the anecdotes. We might add to this idea by suggesting that the properties that become determinate are somewhat more under the control of the researcher who is aware of the social, cultural, and philosophical origins and exclusions of the underlying premises. An individual's view on the meaning of theory is based upon axiological, ontological, epistemological, and teleological presuppositions (or preferences). The acceptability of these preferences is often affected by local, cultural, and geographic positioning. We must become aware of the origins and effects of our theories on praxis and policy: how do our local values affect selection, development, implementation, and the human-culture-machine relationship? 


\section{The Ancestry of Theories}

In addition to lack of awareness of our theoretical lenses, there are other possible issues with the use of theory in educational technology. These include incommensurability of method and theory, lack of depth in reflection ${ }_{1}$ lack of communication between theorists and practitioners, and between theorists of divergent perspectives and differing disciplines; a reliance on jargon and simplified, unclear thinking, and lack of respect for theory and intellectual work (Wilson 1997).

Leading protagonists of mobile learning have sometimes made arbitrary choices about where they look for ancestors and antecedents. Their choices are often driven by a notion that mobile learning is descended from e-learning. So, the arbitrary choices include psychology, artificial intelligence, cognitive psychology, and educational technology, but often sociology, information systems, and anthropology have been less well represented in the field. The derivation of the theory has, as such, followed on logically to include theorists such as Vygotsky, Pask (1976), Laurillard (2002), and Sharples, Taylor and Vavoula (2005). What is problematic is not related to the valuable work of these scholars, but the lack of inclusion of other scholars from the excluded indigenist, feminist, and Southern domains, for example. Furthermore the transition of mobile learning from an innovative e-learning programme to an abiding and defining characteristic of most societies places it a long way from its origins. Even more disturbing is the dismissal of theory within the context of capitalist and neoconservative interests of some of the governments of the North.

Elsewhere (Traxler 2015) we have developed the proposition that large-scale e-learning has been integral to the industrialisation of higher education. It had been conceptualised as such already (Tait 1993, Illich 1971, and Peters 1994) and was in part a response to the prevalent political agenda of participation, inclusion and opportunity. We argue that we are at a point where the first generation of industrialised learning has delivered all it can and we see an emergent second generation. Risking oversimplification, the first generation was characterised by inflexible Fordism, the production line; it was driven by the institutions that managed change from the top, from the centre. This first generation emphasised (the lack of) evidence for policy and for the deployment of technology in learning. This is understandable given the evidence-based context, but increasingly, technology became the ubiquitous social norm, digital divides were 
recognised as complex and counter-intuitive and the role of evidence was changed (or removed).

Manufacturing has become global and just-in-time. This second generation of learning will be user-driven, or rather consumer/customer-driven, perhaps a neo-liberal nightmare of infinite choice; institutions must respond to the unmanaged pressure from outside that comes from increased ownership, familiarity and expectations around universal personal technologies. Increasingly, technology happens outside institutions, inside which students claim that they are forced to power down. Does this represent merely reactions to shifts in the markets of higher education or something more fundamental?

Previously, technology was other; it was a dumb conduit, a dumb container for learning; it merely enhanced or supported learning, and it merely serviced the existing order. Now technology is portrayed as socially transformative; technology is us (Rettie, 2005). The first generation of e-learning was Web1.0, the web (and the educator) as broadcaster and students were readers; the second generation was Web2.0, everyone became writers and readers. As mobile learning becomes normalized, are technologies reshaping us as entities? Now knowledge is created locally, partially, contingently, forme, and for-now. Ideologically, social constructivism was the dominant espoused pedagogy of the North, though behaviourism was probably the dominant enacted pedagogy. Education, psychology and computing were the foundations of e-learning, not sociology or information systems. The second generation was expected to develop new ideologies, perhaps connectivism (Siemens, 2005) or navigationism (Brown, 2006) for the epistemological revolution (Des Bordes and Ferdi, 2008). There is, however, an argument that technology always embodies an ideology, or in this case a pedagogy, and whilst users may appropriate the technology and over-write the ideology, it is certainly not the case that technology is neutral. In fact, we have seen the original MOOC ideology over-written by a more corporate one, and the new ideologies have lost ground and the existing institutions have colonised and co-opted transformative spaces. That at least is the rhetoric and ignores the capacity of institutions to appropriate and colonise these new forms and genres. Instead, participative media are being transformed back into the outlets for the corporate message. This clearly impacts on how mobile learning is defined and perceived, and the place, if any, of its theories. 


\section{The Ethics Implicit in Theories and Definitions}

In looking at our analysis of theory, the standpoint of our epistemology is inherently Northern and Western - a perspective that is embedded into technologies and pedagogies. We must address this bias and attempt to frame analysis within a more fluid and complex context, even in the North. We implicitly assume that the western/European model of universities and their modes of reasoning and theorising are necessarily the sole or best expression of a culture's or a community's higher learning and of its intellectual enquiry and endeavours. In the days before e-learning, educational interventions in distant and different communities were difficult and thus the danger to indigenous epistemology and theory was remote. Mobile learning now makes these interventions and activities easy, and thus any local and marginal, and indigenous forms of understanding and learning are threatened. Education is in many ways a process of acculturation and identity transformation of non-traditional working class and indigenous students in the North and of those in the South. How do we reconcile accessing national educational opportunities and the theoretical biases to exploit these with the preservation of culture and local theory?

In light of this history of distance education and mobile learning, we return to the conventional versus the contingent at the practical level. Theories of 'conventional' elearning rest on the experience of stable technology platforms; the dominant and enduring nature of operating systems along with their input and output conventions and other computing standards. E-learning appears to take place in a technological environment that is consistent, homogeneous and transparent; the technology no longer gets in the way. The technology platform upon which mobile learning theory might rest could be, by comparison, volatile, inconsistent and haphazard; otherwise, the work of understanding mobile learning, couched in the terms and practices of conventional technologies, is impeded. Theorizing about mobile learning compared to e-learning is problematised by the fact that mobiles are a massive social and popular phenomenon, not a merely minor educational and institutional one, where attitudes, usage and expectations are characterized by appropriation, fragmentation, and transience. Mobile learning needs a 'theory of technology' that is based in its own terminology, to anchor it amidst the constant flux of actual technological change. 


\section{Sourcing Our Theories}

We could argue that the mobile learning community in looking for theory is, to oversimplify, faced with three different options: import theory from "conventional" elearning and worry about transferability to m-learning; develop theory ab initio locally (culturally and economically specific) and worry about validity and generalisability; or subscribe to some much more general and abstract theory and worry about specificity and granularity (applicability to local problems). Although the last fifteen years have brought important advancements, a re-examination is needed of what mobile learning theory is and could be, by revisiting the various existing theories of mobile learning and the definitions that underpin them.

\section{Conclusions and Recommendations}

This paper was developed as a reaction and response to the perception that discussions, accounts and analyses of mobile learning were built on very problematic foundations and these were a consequence of flawed use of language, particularly around definition, cause and theory. Different communities have different needs, expectations, contexts and history that influence how these words and ideas are used and understandably discussion and debate have lacked adequate rigour, clarity and perhaps skepticism. That is our conclusion and any recommendation at this stage must be perhaps for more proficiency, practice and expertise in the use of language and reasoning amongst and between the various communities seeking to develop and deploy mobile technologies for learning.

\section{REFERENCES}

Ally, M. (Ed.) 2009. Mobile Learning: Transforming the Delivery of Education and Training. http://www.aupress.ca/index.php/books/120155 (accessed June 30, 2017)

Barad, K. 2007. Meeting the Universe Halfway: Quantum Physics and the Entanglement of Matter and Meaning. Durham, UK: Duke University Press.

Brown, T. 2006. Beyond Constructivism. Navigationism in the Knowledge Era. On the Horizon 14(3): 108-120.

Büscher, M., and J. Urry. 2009. Mobile Methods and the Empirical. European Journal of Social Theory 12(1): 99-116.

Butler, C. 2002. Postmodernism: A Very Short Introduction. New York: Oxford University Press.

Cobcroft, R. 2006. Literature Review into Mobile Learning in a University Context. 
Queensland University of Technology. http://eprints.qut.edu.au/archive/00004805 (accessed June 30, 2017).

Cochrane, T., Jones, S., Kearney, M., Farley, H. \& Narayan, V. (2016). Beyond Pokémon Go: Mobile AR \& VR in Education. In S. Barker, S. Dawson, A. Pardo, \& C. Colvin, eds. Show Me The Learning. Proceedings ASCILITE 2016 Adelaide, pp. 136-138.

Cook, J. (2010). Mobile Learner Generated Contexts. In Medienbildung in neuen Kulturräumen pp. 113-125. VS Verlag für Sozialwissenschaften

Crompton, H. 2013. A Historical Overview of M-learning: Toward Learner-Centred Education. In Handbook of Mobile Learning, ed. Z. L. Berge and L. Y. Muilenburg, 314. New York: Taylor and Francis.

Des Bordes, A., and S. Ferdi. 2008. Do Knowledge and New Technologies Need a New Epistemology? In Proceedings of BOBCATSSS 2008: Providing Access to Information for Everyone, Zadar, Croatia. http://edoc.hu-

berlin.de/conferences/bobcatsss2008/des-bordes-anne--115/PDF/des-bordes.pdf (accessed June 30, 2017).

Dykes, G., and H. R. Knight. 2012. Mobile Learning for Teachers in Europe: Exploring the Potential of Mobile Technologies to Support Teachers and Improve Practice. Paris: UNESCO.

Fritschi, J., and M. A. Wolf. 2012a. Mobile Learning for Teachers in North America: Exploring the Potential of Mobile Technologies to Support Teachers and Improve Practice. Paris: UNESCO.

Fritschi, J., and M. A. Wolf. 2012b. Turning on Mobile Learning in North America: Illustrative Initiatives and Policy Implications. Paris: UNESCO.

Genachowski, C. J. 2010. Mobile Broadband: A 21st Century Plan for US Competitiveness, Innovation and Job Creation. Washington DC: Speech, New America Foundation.

Hannam, K., M. Sheller, and J. Urry. 2006. Editorial: Mobilities, Immobilities and Moorings. Mobilities 1(1): 1-22.

Herrington, J., A. Herrington, J. Mantei, I. Olney, and B. Ferry, eds. 2009. New Technologies, New Pedagogies: Mobile Learning in Higher Education. Wollongong: Faculty of Education, University of Wollongong. http://ro.uow.edu.au/newtech/ (accessed June $30,2017)$

Hylén, J. 2012. Turning on Mobile Learning in Europe: Illustrative Initiatives and Policy Implications. Paris: UNESCO.

Isaacs, S. 2012a. Mobile Learning for Teachers in Africa and the Middle East: Exploring the Potential of Mobile Technologies to Support Teachers and Improve Practice. Paris: UNESCO.

Isaacs, S. 2012b. Turning on Mobile Learning in Africa and the Middle East: Illustrative Initiatives and Policy Implications. Paris: UNESCO.

Jara, I., M. Claro, and R. Martinic. 2012. Mobile Learning for Teachers in Latin America: Exploring the Potential of Mobile Technologies to Support Teachers and Improve Practice. Paris: UNESCO.
Formatted: Font color: Auto

Formatted: Font:Italic

Deleted: Cochrane [incomplete - MP]

Formatted: Font:Italic

Deleted:

Deleted: c 
Kirby, A. 2009. Digimodernism: How New Technologies Dismantle the Postmodern and Reconfigure our Culture. New York: Bloomsbury.

Kukulska-Hulme, A., M. Sharples, M. Milrad, I. Arnedillo-Sánchez, and G. Vavoula. 2011. The Genesis and Development of Mobile Learning in Europe. In Combining E-Learning and M-Learning: New Applications of Blended Educational Resources, ed. D. Parsons, 151-177. Hershey, PA: Information Science Reference (an imprint of IGI Global).

Illich, I. 1973. Tools for Conviviality. New York: Harper and Row.

Kuhn, T. S. 2012. The Structure of Scientific Revolutions. Chicago, ILL: University of Chicago Press.

Laurillard, D. 2002. Rethinking University Teaching: A Conversational Framework for the Effective Use of Learning Technologies. 2nd edition. London: Routledge Falmer.

Lugo, M. T., and S. Schurmann. 2012. Turning on Mobile Learning in Latin America: Illustrative Initiatives and Policy Implications. Paris: UNESCO.

Metcalf, D. S. 2006. MLearning: Mobile Learning and Performance in the Palm of your Hand. Amherst, MA: HRD Press.

Neuman, L. W. 2003. Social Research Methods: Qualitative and Quantitative Approaches. Boston, MA: Pearson.

Pachler, N., B. Bachmair, J. Cook, and G. Kress, eds. 2010. Mobile Learning - Structures, Agency, Practices. London: Springer.

Pask, G. 1976. Conversational Techniques in the Study and Practice of Education. British Journal of Educational Psychology 46: 12-25.

Peters, O. 1994. Distance Education and Industrial Production: A Comparative Interpretation in Outline (1973). In Otto Peters on Distance Education: The Industrialization of Teaching and Learning, ed. D. Keegan, 107-127. London: Routledge.

Rettie, R. 2005. Presence and Embodiment in Mobile Phone Communication. Psychology Journal 3(1): 16-34.

Rose, H., and S. P. Rose. 1976. The Political Economy of Science: Ideology of/in the Natural Sciences. London: Macmillan.

Quinn, C. 2012. The Mobile Academy: MLearning for Higher Education. San Francisco, CA: Jossey-Bass.

Siemens, G. 2005. Connectivism: A Learning Theory for the Digital Age. International Journal of Instructional Technology and Distance Learning 2(1). http://www.itdl.org/Journal/Jan_05/article01.htm (accessed June 30, 2017).

Sharples, M., J. Taylor, and G. Vavoula. 2005. Towards a Theory of Mobile Learning. http://www.mlearn.org.za/CD/papers/Sharples-Theory of Mobile.pdf (accessed June 30, 2017).

Shuler, C. 2009. Pockets of Potential: Using Mobile Technologies to Promote Children's Learning. New York: The Joan Ganz Cooney Center at Sesame Workshop. 
Storey, J. 2000. The Management of Innovation Problem. International Journal of Innovation Management 4(3): 347-369.

So, H. J. 2012. Turning on Mobile Learning in Asia: Illustrative Initiatives and Policy Implications. Paris: UNESCO.

Sorell, T. 2013. Scientism: Philosophy and the Infatuation with Science. London: Routledge.

Tait, A. 1993. Systems, Values and Dissent: Quality Assurance for Open and Distance Learning. Distance Education 14(2): 303-314.

Tough A. 1979. The Adult's Learning Projects. Ontario: Ontario Institute for Studies in Education.

Toyama, K. 2015. Geek Heresy: Rescuing Social Change from the Cult of Technology. New York, NY: PublicAffairs

Traxler, J. 2008. Mobile Learning in a Mobile World - The Practicalities of the Social, Ethical and Legal Environment. In Handbook of Research on Digital Information Technologies: Innovations, Methods, and Ethical Issues, ed. T. Hansson. Hershey, PA: Information Science Reference.

Traxler, J. 2016. Mobile Learning Research: The Focus for Policy-Makers. Journal of Learning in Development 3(2).

Traxler, J. 2016. Learning with Mobiles in Developing Countries -Technology, Language and Literacy. International Journal of Mobile and Blended Learning. 9(2): 1-15

Traxler, J., and A. Kukulska-Hulme. 2006. The Evaluation of Next Generation Learning Technologies: The Case of Mobile Learning. In Research Proceedings of ALT-C2006. Oxford: ALT.

Traxler, J. and Lally, V. 2015. The Crisis and the Response: After the Dust Had Settled, Interactive Learning Environments 24(5): 935-937.

Traxler, J. 2008. Learning in a Mobile Age. International Journal of Mobile and Blended Learning 1(1): 1-12.

Traxler, J. 2011. Mobile Learning: Starting in the Right Place, Going in the Right Direction? International Journal of Mobile and Blended Learning 3(1): 57-67.

Urry, J. 2007. Mobilities. London: Polity.

Weick, K. E., and K. M. Sutcliffe. 2005. Organizing and the Process of Sensemaking. Organizational Science 16(4): 409-421.

Wilson, B. G. 1997. Thoughts on Theory in Educational Technology. Educational Technology 37(1): 22-26. http://carbon.ucdenver.edu/ bwilson/theory.html (accessed June 30, 2017).

\section{Formatted: Font:Not Italic}

Deleted: [Incomplete-MP]

Formatted: Font:Italic

Formatted: Font:Not Italic

Deleted: [incomplete - MP]

\section{Formatted: Font:Italic}

Deleted: Traxler, J, and V. Lally. 2015. The Crisis and the Response: After the Dust Had Settled. [incomplete MP]Interactive Learning Environments. 